Indústria e Desenvolvimento Econômico:

desafios e perspectivas

18 a 20 de setembro de 2018

Uberlândia - Minas Gerais

ÁREA: 6.2: Políticas de Ciência, Tecnologia e Inovação

JEL: O30; O21; 038;

\title{
O BANCO DE DESENVOLVIMENTO DE MINAS GERAIS E SUA ATUAÇÃO NO FOMENTO Á INOVAÇÃO
}

Leandro Alves Silva (Cedeplar/UFMG)

Aline Rocha de Resende Costa (FACE/UFMG)

\section{RESUMO}

Este trabalho tem o objetivo de analisar o financiamento da inovação do Banco de Desenvolvimento de Minas Gerais (BDMG), no período de 2011 até 2016. Atualmente, são três formas de atuação: linhas de crédito, aporte em fundos de investimento e participação direta no capital social de duas empresas de tecnologia. Os dados foram cordialmente cedidos pela instituição para elaboração deste trabalho, cuja ênfase está na carteira de crédito. As linhas de financiamento são abordadas segundo critérios de distribuição setorial e geográfico. Além disso, aplicou-se um questionário inédito nas empresas financiadas pelo banco, para identificar características qualitativas do financiamento e possíveis padrões, como a relação entre ter experiência com projetos de inovação e o maior grau inovativo do projeto - inovação para o mercado nacional ou para mundo, por exemplo.

Palavras-chave: Desenvolvimento econômico; Economia da ciência e tecnologia; Banco de Desenvolvimento de Minas Gerais; Financiamento da inovação

\begin{abstract}
This work analyzes the financing of innovation investments of Minas Gerais Development Bank (BDMG) during the period from 2011 to 2016. Currently, there are three ways the bank acts: through credit lines, investment funds and direct participation on non-equity capital of two technology companies. Because of the availability of data, cordially provided by BDMG for the elaboration of this paper, credit portfolio will be emphasized. The study lines' approach follows the distribution criteria of the sectorial and the geographic scenario. In addition, an inedited survey was applied to the companies financed by the bank to identify the quality of finance and possible tendencies, such as a relationship between experience with innovation projects and the innovative degree of the project itself (for example, innovation for the national market or at a global level).
\end{abstract}

Keywords: Economic development; Economics of science and technology; Development Bank of Minas Gerais; Financing innovation 


\section{1 - Introdução}

A mudança tecnológica e a inovação desempenham um importante papel no crescimento econômico. Cada vez mais a geração de conhecimento e inovações proporcionam oportunidades para novos investimentos. Contudo, o processo de inovação é permeado pela incerteza e os seus resultados nem sempre podem ser antecipados. Fomentá-lo e financiá-lo consiste em um desafio para as instâncias financeiras, que, no geral, não pode ser enfrentado com os instrumentos tradicionais. As atividades voltadas à inovação são financiadas de modo distinto e instrumentos financeiros específicos para esse fim têm sido desenvolvidos.

Os Bancos de Desenvolvimento são instituições com grande potencial para financiar os investimentos em inovação porque possuem "maior capacidade de assumir riscos relacionados a aspectos políticos, econômicos e geográficos" (Mazzucato, 2014:191). Como não tem a obrigação de remunerar investidores privados com dividendos, podem assumir riscos mais elevados do que os bancos comerciais de forma a atender objetivos de "bem público" (Idem, pg. 191). Desta forma conseguem prover as empresas do que Mazzucato (2014) denomina de capital paciente, recurso comprometido que dá o tempo necessário para que as empresas superem as incertezas inerentes ao processo de inovação. Segundo a mesma autora os Bancos de Desenvolvimento podem financiar mais do que projetos porque podem financiar também as etapas de produção, sendo "financistas flexíveis" (Idem: 192).

Tendo estas considerações em mente, este artigo tem como objetivo caracterizar as atuações do Banco de Desenvolvimento de Minas Gerais (BDMG) no fomento do processo inovativo e oferecer insights sobre como o financiamento da inovação pode contribuir para o desenvolvimento em Minas Gerais. A elaboração deste artigo foi possível graças à disponibilização dos dados pelo BDMG. Para avaliar o caráter qualitativo das linhas de crédito de inovação, aplicou-se, a partir da colaboração do BDMG e da Gerência de Análises e Estudos, um questionário aos clientes que obtiveram financiamento com este fim, a partir de 2011 (quando as linhas de crédito especificas para inovação foram criadas).

Além dessa introdução o presente trabalho possui outras quatro seções. A segunda seção discorre brevemente sobre a importância do financiamento público à inovação em vista de suas especificidades que dificultam definir ex-ante o lucro e o custo da inovação. A terceira seção discorre sobre as formas de atuação do BDMG no fomento da inovação: as linhas de crédito com juros subsidiados; os Fundos de Investimento em Participações (FIPs) e os Fundos de participações diretas no capital social de empresas. A quarta seção apresenta os resultados do questionário aplicado nas empresas que foram financiadas pelas linhas de crédito do BDMG para inovação, no período de 2011 até 2016 e a quinta seção apresenta as conclusões e considerações finais do trabalho.

\section{2 - Financiamento à Inovação}

O processo de inovação é incerto, acontece no longo prazo e é coletivo e cumulativo (Lazonick and Mazzucato, 2013), evidenciando que o tipo de financiamento necessário não é simples ou trivial. A incerteza característica compromete de forma irremediável o cálculo ou a previsão dos resultados, dos custos e dos riscos do processo de inovação. A natureza cumulativa e de longo prazo significa que o financiamento exige um "capital paciente", enquanto o caráter coletivo um conjunto variado de fontes privadas e públicas para o financiamento da inovação.

Chesnais e Sauviat (2005:165) sintetizam os arranjos institucionais que permitiram o financiamento privado em inovação de longo prazo. A primeira, e mais antiga, é através dos lucros retidos nas empresas que são destinados à inovação e aos investimentos em P\&D. Esta hipótese é corroborada com estudos empíricos que convergem no sentido de mostrar que grande parte dos gastos com inovação são autofinanciados pelas empresas, a partir de lucros retidos (Himmelberg e Petersen, 1994). Contudo, essa forma de financiamento está sendo comprometida com a exacerbação da estratégia de "maximização do valor da acionista", adotada pelas grandes empresas. Ao invés de 
investirem seus lucros retidos em projetos de $\mathrm{P} \& \mathrm{D}$ de longo prazo, as empresas fazem recompra de suas ações de forma a garantir a manutenção do seu valor no mercado e, consequentemente, a remuneração do acionista (Mazzucato, 2014).

Outra forma também tradicionalmente utilizada por alguns países é através de empréstimos de longo prazo de bancos que cultivaram relações próximas com as empresas. Estas relações ao permitirem a repetição de contratos entre os tomadores e os fornecedores de empréstimo, possibilitaram a acumulação de conhecimento através do aprendizado interativo sobre inovação por parte dos bancos. A assimetria de informação que estaria na origem do racionamento de crédito seria, em parte, superada pela criação de canais de comunicação e informação entre as partes (CHRISTENSEN, 1992).

A forma mais recente é o financiamento de investimentos para a inovação através dos mercados financeiros. Dentre as formas disponíveis para as empresas, desde anos 80 tem-se o mercado internacional de títulos privados, de acesso restrito às empresas com forte reputação. Para as empresas nascentes, em vários países, iniciou-se a expansão da oferta de capital de risco, seja por grandes empresas visando a aquisição de tecnologia de ponta, ou por investidores institucionais via fundos financeiros. Uma outra forma, em sinergia com o capital de risco, é o levantamento de recursos através da emissão de ações em mercados financeiros especializados, como o NASDAQ, por exemplo, com condições de retorno aceitável aos investidores financeiros. Contudo, Leonel (2014) já demostrou que, paradoxalmente, o capital de risco não financia as etapas de maior risco do processo de inovação, estando restrito a setores de rápido crescimento.

Por sua vez, o financiamento público, em um grande número de países, é de longo prazo e reúne uma diversidade de modalidades. Um conjunto amplamente utilizado são os programas para induzir as empresas a realizarem atividades de P\&D através de empréstimos a juros mais baixos, oferta de recursos não-reembolsáveis e incentivos fiscais, tradicionalmente utilizados em praticamente todos os países. Além disso, pode-se mencionar a destinação de recursos para o financiamento de P\&D nas empresas utilizando programas de compras governamentais e o suporte mais indireto ao estabelecimento de infraestrutura de P\&D para o desenvolvimento industrial. Os Bancos de Desenvolvimento estão dentre as instituições que podem fornecer crédito a taxas mais acessíveis, mediante a seleção de projetos de empresas com potencial impacto de gerar inovação de produto ou de processo.

\section{3 - O Banco de Desenvolvimento de Minas Gerais (BDMG)}

O Banco de Desenvolvimento de Minas Gerais (BDMG) é uma empresa pública estadual fundada em 1962. Um dos poucos bancos de desenvolvimento que permaneceu ativo no Brasil, ele possui como missão participar do desenvolvimento econômico e social do estado.

Segundo Relatório de Gestão do BDMG (2016), o banco apoia projetos de investimento do setor público municipal e concede financiamento para investimento e/ou capital de giro para empresas privadas. Além das linhas de crédito, que atendem clientes de diversos portes e setores econômicos, o banco participa de fundos de investimentos em inovação e sustentabilidade, possui participação acionária no BHTEC, parque tecnológico que se localiza em Belo Horizonte, e estrutura projetos de concessão e parcerias público-privadas (PPPs) na área de infraestrutura.

O banco desembolsa em torno de $\mathrm{R} \$ 1,2$ até $\mathrm{R} \$ 2$ bilhões anuais. Em 2016, do total desembolsado ( $\mathrm{R} \$ 1,4$ bilhão), 74\% correspondeu a operações de repasses do Banco Nacional de Desenvolvimento Econômico e Social (BNDES), da Fundação de Amparo à Pesquisa do Estado de Minas Gerais (FAPEMIG), da Financiadora de Estudos e Pesquisas (Finep), do Ministério da Agricultura e Pecuária e da Caixa Econômica Federal (CEF). Já, as operações com recursos próprios representam apenas $24 \%$ do desembolso total.

Em relação a distribuição de recursos por porte da empresa, o BDMG destinou, em 2016, R\$1,01 bilhão (69\%) para grandes e médias empresas, $\mathrm{R} \$ 280,4$ milhões $(19 \%)$ para micro e pequenas empresas. Os empréstimos para o setor público atingiram $11 \%$, enquanto $1 \%$ foi direcionado para aporte de participações diretas e indiretas. Os principais setores atendidos foram: comércio e serviços, 
$38 \%$ dos desembolsos totais, seguido pelos setores da indústria de transformação, com 36\%, e dos serviços industriais de utilidade pública, com 13\%. A construção civil e a agricultura, pecuária e silvicultura tiveram participação percentual de $8 \%$ e $5 \%$, respectivamente.

Em 2016, as operações destinadas à inovação somaram, aproximadamente, $\mathrm{R} \$ 50$ milhões de reais o que representa $3,57 \%$ do desembolso total do BDMG. Financiou-se 41 projetos em 16 municípios mineiros no mesmo ano. O papel da inovação dentro do banco, mesmo que percentualmente pequeno, teve crescimento tanto no valor desembolsado, quanto no número de projetos financiados em relação ao ano anterior, de $45 \%$ e $41 \%$, respectivamente. O aumento do desembolso, possivelmente, está associado a introdução do produto da FINEP, em 2014. Como mostrado adiante, a linha de crédito possui ticket médio ${ }^{1}$ igual a $\mathrm{R} \$ 2,1$ milhões, mais que o dobro do segundo produto de inovação mais popular - o Pró-Inovação, que possui ticket médio igual a $\mathrm{R} \$ 0,65$ milhão. Já, o crescimento do número de projetos provavelmente está associado a mudança organizacional da meta comercial, que teve início em 2016.

A partir do estudo do BDMG com o Centro de Planejamento de Desenvolvimento Regional da UFMG (Cedeplar) ${ }^{2}$ em 2016, que utiliza a metodologia da Matriz Insumo Produto (2008), quantificou-se que, em média, a cada um real que o banco de desenvolvimento insere na economia, são gerados outros 0,99 centavos adicionais na produção estadual (multiplicador aproximadamente 2). Em outra frente, o papel dos bancos públicos vai sendo revertido pelo Governo Federal, em 2017. A devolução antecipada de $\mathrm{R} \$ 100$ bilhões pelo BNDES ao Tesouro Nacional e a substituição da TJLP pela TLP são alguns exemplos. Dessa forma, um dos maiores desafios impostos ao BDMG, na atualidade, é a busca por fundings alternativos.

\section{1 - O BDMG e o fomento da inovação}

Inaugurada em 2011, a concessão de crédito para o fomento da inovação pelo BDMG, destinase ao apoio a projetos de inovação ou a empresas inovadoras, com fundings do BNDES, da FINEP e da FAPEMIG. A distinção entre projeto inovador e empresa inovadora é relevante, pois os pedidos de concessão de crédito são tratados de maneira diferente. Quando a empresa é inovadora, não é necessário a avaliação da mesma por um comitê técnico, basta que ela se enquadre nos requisitos definidos pelos editais do BNDES e/ou da FINEP, dependendo do caso, ou esteja localizada em parque tecnológico. Para projeto inovador o comitê técnico que, além de funcionários do banco, pode ser composto por membros das instituições fundings, julga se o projeto é ou não inovador. Por fim, em ambos os casos o processo de concessão ainda passa pela análise de crédito, onde define-se o limite máximo a ser financiado, e o risco daquele financiamento para o BDMG conforme FIG. 1. Um resumo das linhas de financiamento da inovação ofertadas pelo BDMG é apresentado na TAB. 1.

\footnotetext{
1 Termo que se refere ao desembolso dividido pelo número de projetos financiados.

2 Retornos dos Desembolsos do BDMG para Economia de Minas Gerais: 2007-2016. Banco de Desenvolvimento de Minas Gerais. Belo Horizonte. 2016
} 
Figura 1: Organograma da Liberação de Crédito do BDMG para Inovação

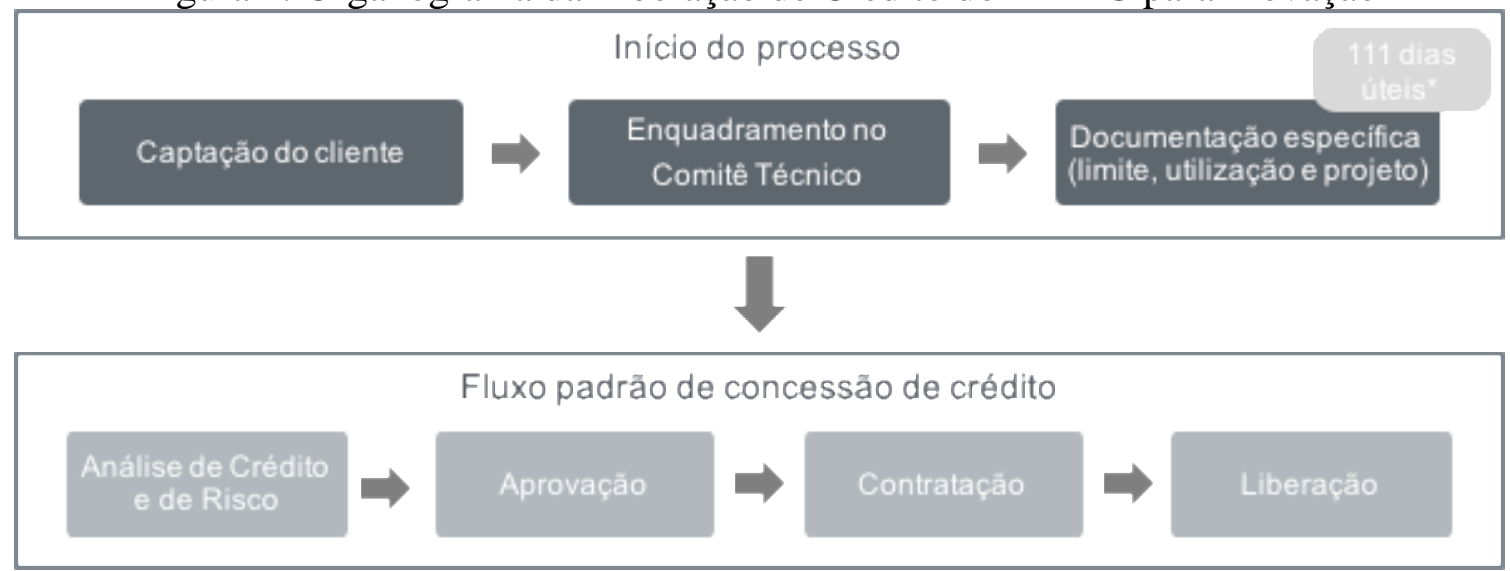

Fonte: Elaboração própria a partir de informações disponibilizadas pelo BDMG

Para ser considerada empresa inovadora pela linha MPME Inovadora (Micro e Pequena Empresa Inovadora) do BNDES é necessário, que as empresas que tenham receita anual até R $\$ 90$ milhões e que, nos últimos cinco anos, atendam a algum dos seguintes requisitos: tenham contratado serviços tecnológicos no âmbito do Produto Cartão BNDES; tenham sido apoiadas por outros programas de inovação (listados no site do BNDES); tenham, pelo menos, depositado no INPI pedido de patente ou registro de programa de computador; estejam localizadas em parques tecnológicos; estejam incubadas ou tenham sido graduadas nas incubadoras certificadas pelo BNDES ou tenham em sua composição societária, algum dos Fundos de Investimento em Participações e/ou Fundos Mútuos de Investimento em Empresas Emergentes regulados pela CVM (Comissão de Valores Mobiliários).

Para linha Inovacred Expresso da FINEP, a empresa com receita anual menor ou igual a R \$16 milhões deve, nos últimos cinco anos, ter recebido apoio governamental (incentivos fiscais, bolsas RHAE para pesquisadores em empresas, financiamento no MPME inovadora, dentre outros), ter pelo menos, depositado patente no INPI ou estar instalada em incubadoras de base tecnológica ou parques tecnológicos. ${ }^{3}$

O Programa de Apoio à Empresas em Parques Tecnológicos (Proptec) da FAPEMIG é um produto exclusivo do BDMG. Ele tem como objetivo apoiar propostas de implantação, ampliação e modernização de empresas localizadas em Parques Tecnológicos mineiros - o único critério de seleção do produto. Todavia, essa característica do produto é limitante, pois segundo portal do Sistema Mineiro de Inovação (SIMI) ${ }^{4}$, Minas Gerais possui apenas três Parques Tecnológicos em Uberaba, Itajubá e Belo Horizonte.

As duas linhas de crédito que apoiam projetos inovadores são o Inovacred da FINEP e o PróInovação da FAPEMIG. Apesar de financiarem o desenvolvimento de novos produtos, processos e/ou serviços as duas linhas possuem diferenças significativas. O conceito de inovação, por exemplo, é heterogêneo. A FINEP considera inovações em marketing e no âmbito organizacional segundo o edital e deixa os critérios de seleção dos itens financiáveis sujeito a interpretação dos agentes bancários - desde que as atividades da empresa contribuam para geração de conhecimento ou aprimoramento do mesmo. A FAPEMIG é menos flexível na determinação do que pode ser financiado. Determina-se que o recurso deve ser usado para aquisição de máquinas e equipamentos, obras civis, veículos, informatização e/ou pesquisa e desenvolvimento. Além disso, até $30 \%$ do valor solicitado pode ser usado como capital de giro para apoiar o projeto de inovação.

Outra grande diferença entre as duas linhas é o valor máximo financiável, que influencia o ticket médio do produto e o porte das empresas financiadas. Enquanto, o Inovacred (FINEP) empresta até $\mathrm{R} \$ 10$ milhões, para empresas que possuem receita operacional bruta anual (ROB) de até $\mathrm{R} \$ 90$ milhões, o Pró-Inovação (FAPEMIG) concede empréstimos de até R \$2 milhões, com aval dos sócios

\footnotetext{
${ }^{3}$ Vale ressaltar, que esse produto financiou apenas duas empresas até o final de 2016.

4 << http://www.simi.org.br >> acesso dia 07/06/2017
} 
como garantia para valores até $\mathrm{R} \$ 1$ milhão, benefício que faz o ticket médio do produto ser menor e atender, principalmente, micro e pequenas empresas.

Vale ressaltar, que Pró-Inovação (FAPEMIG), assim como o Proptec (FAPEMIG), são linhas de crédito exclusivas do BDMG. Todas os outros produtos financeiros podem ser ofertados por bancos comerciais e outras instituições de fomento fora de Minas Gerais. A diferença, e isso é relevante, consiste na avaliação do crédito e do risco que cada agência ou banco faz dos projetos, além do spread cobrado. Isso faz com que o mesmo produto, seja ofertado a preços diferentes no sistema bancário. Um exemplo, é o Inovacred (FINEP) que é ofertado pela Agência Paulista de Desenvolvimento ${ }^{5}$ a $0,57 \%$ a.m., enquanto oferta-se no BDMG o mesmo produto a uma taxa de 0,65\% a.m. O Quadro 1 resume as linhas para inovação ofertadas no BDMG.

Quadro 1: Descrição dos Produtos Financeiros de Inovação do BDMG (2016)

\begin{tabular}{|c|c|c|c|}
\hline $\begin{array}{l}\text { Funding e } \\
\text { Produto }\end{array}$ & Funding e Produto Financeiro & \multicolumn{2}{|c|}{ Funding e Produto Financeiro } \\
\hline \multirow{3}{*}{$\begin{array}{l}\text { FINEP > } \\
\text { INOVACRED }\end{array}$} & \multirow{3}{*}{$\begin{array}{l}\text { Financia a introdução de novos produtos, processos, serviços, } \\
\text { marketing ou inovação organizacional, ou aperfeiçoamento da } \\
\text { tecnologia existente. Atende empresas com ROB de até } \mathrm{R} \$ 90 \\
\text { milhões e possui limite máximo de desembolso, por empresa, de até } \\
\mathrm{R} \$ 10 \text { milhões. }\end{array}$} & TAXA: & a partir de $0,65 \%$ a.m. \\
\hline & & PRAZO: & até 96 meses* \\
\hline & & CARÊNCIA: & até 24 meses \\
\hline \multirow{3}{*}{$\begin{array}{l}\text { FINEP > } \\
\text { INOVACRED } \\
\text { EXPRESSO }\end{array}$} & \multirow{3}{*}{$\begin{array}{l}\text { Linha de crédito complementar ao Inovacred, que financia } \\
\text { operações de até } \mathrm{R} \$ 150 \text { mil e com fluxo operacional simplificado } \\
\text { para empresas com receita bruta anual de até } \mathrm{R} \$ 16 \text { milhões. }\end{array}$} & TAXA: & a partir de $0,91 \%$ a.m. \\
\hline & & PRAZO: & até 48 meses* \\
\hline & & CARÊNCIA: & até 12 meses \\
\hline \multirow{3}{*}{$\begin{array}{l}\text { BNDES > } \\
\text { MPME } \\
\text { INOVADORA }\end{array}$} & \multirow{3}{*}{$\begin{array}{l}\text { Financia empresas inovadoras com faturamento anual de até } \mathrm{R} \$ 90 \\
\text { milhões, que buscam introduzir novas tecnologias ou processos } \\
\text { inovadores na produção ou prestação de serviços. Limite máximo } \\
\text { de } \mathrm{R} \$ 10 \text { milhões por beneficiário, a cada } 12 \text { meses. }\end{array}$} & TAXA: & a partir de $1,00 \%$ a.m. \\
\hline & & PRAZO: & até 120 meses* \\
\hline & & CARÊNCIA: & até 48 meses \\
\hline \multirow{3}{*}{$\begin{array}{l}\text { FAPEMIG > } \\
\text { PRÓ- } \\
\text { INOVAÇÃO }\end{array}$} & \multirow{3}{*}{$\begin{array}{l}\text { Financia projetos de inovação, cuja os gastos podem contemplar } \\
\text { investimentos fixos, intangíveis e capital de giro relacionados } \\
\text { diretamente com atividades inovativas. O limite máximo individual } \\
\text { do desembolso é igual a } \mathrm{R} \$ 2 \text { milhões. }\end{array}$} & TAXA: & a partir de $0,68 \%$ a.m. \\
\hline & & PRAZO: & até 60 meses* \\
\hline & & CARÊNCIA: & até 12 meses \\
\hline \multirow{3}{*}{$\begin{array}{l}\text { FAPEMIG > } \\
\text { PROPTEC }\end{array}$} & \multirow{3}{*}{$\begin{array}{l}\text { Financia empresas que obtiveram avaliação técnica positiva pelos } \\
\text { Conselhos Científico Tecnológico dos parques tecnológicos. Possui } \\
\text { limite individual máximo de } \mathrm{R} \$ 2 \text { milhões. }\end{array}$} & TAXA: & a partir de $0,76 \%$ a.m. \\
\hline & & PRAZO: & até 60 meses* \\
\hline & & CARÊNCIA: & até 12 meses \\
\hline
\end{tabular}

Fonte: Elaboração própria a partir de dados disponibilizados pelo BDMG

* incluindo carência

Destaca-se que a totalidade das linhas possuem uns aspectos em comum: taxa de juros subsidiada, flexibilidade do prazo de pagamento, tempo de carência e a condicionalidade do crédito. Em relação a taxa de juros, percebe-se que os produtos da FAPEMIG são os únicos que possuem taxa pré-fixada, entre $8 \%$ a.a. e $9 \%$ a.a., enquanto as linhas da FINEP e do BNDES estão atreladas a TJLP, o que faz com que elas acompanhem as flutuações da conjuntura econômica.

Até dezembro de 2016, o BDMG apoiou através de suas linhas de financiamento 170 projetos de inovação, desembolsando $\mathrm{R} \$ 169,5$ bilhões em valores correntes no período de seis anos para 148 empresas. Treze empresas captaram crédito para inovação pelo menos mais de uma vez - sendo que uma delas teve 6 operações no período analisado. A Tabela 1 apresenta, por produto financeiro do BDMG, o número de projetos financiados, desembolso total acumulado e ticket médio. Atualmente, o estoque desembolsado pelo Inovacred (FINEP) já ultrapassa o Pró-Inovação (FAPEMIG), que foi inaugurado três anos antes. Essa situação é observada porque o produto financeiro da FINEP possui maior limite de crédito e, consequentemente, ticket médio superior. Apesar disso, o Pró-Inovação ainda é o produto com maior número de projetos de inovação.

\footnotetext{
${ }^{5}$ << http://www.desenvolvesp.com.br/empresas/opcoes-de-credito/para-sua-empresa-inovar/>> acesso dia 15/05/2017
} 
Tabela 1: Produto financeiro do BDMG por número de projetos de inovação, desembolso em R \$ valores correntes e ticket médio acumulados (2011-2016).

\begin{tabular}{lccr}
\hline \multicolumn{1}{c}{ Produto } & No $^{\mathbf{0}}$ Projetos & $\begin{array}{c}\text { Desembolso } \\
(\mathbf{R} \mathbf{)})\end{array}$ & \multicolumn{1}{c}{$\begin{array}{c}\text { Ticket médio } \\
\text { desembolsado (R\$) }\end{array}$} \\
\hline BNDES MPME INOVADORA & 22 & $26.973 .463,08$ & $1.226 .066,50$ \\
FINEP INOVACRED & 33 & $69.447 .658,00$ & $2.104 .474,48$ \\
PRO-INOVAÇÃO & 98 & $64.074 .233,27$ & $653.818,71$ \\
PROPTEC & 17 & $9.029 .210,00$ & $531.130,00$ \\
Total & $\mathbf{1 7 0}$ & $\mathbf{1 6 9 . 5 2 4 . 5 6 4 , 3 5}$ & $\mathbf{9 9 7 . 2 0 3 , 3 2}$ \\
\hline
\end{tabular}

Fonte: Elaboração própria a partir de dados disponibilizados pelo BDMG

O Gráfico 1 apresenta os desembolsos anuais em valores correntes por linha de crédito. Destaca-se a tendência de crescimento contínuo do desembolso do Inovacred nos últimos três anos, apesar da quantidade de projetos apoiados serem o mesmo em 2014 e 2015. Já, em 2016, quando o indicador de meta comercial começa a avaliar número de projetos e não apenas desembolso, o número passa de 9 projetos apoiados/ano para 15 projetos/ano. ${ }^{6}$ Porém, em 2016, o ticket médio atinge o valor de $\mathrm{R} \$ 2,3$ milhões - menor do que o ano anterior ( $\mathrm{R} \$ 2,6$ milhões).

O Inovacred Expresso que financiou apenas duas empresas inovadoras, em 2016, está representado no GRAF. 1, em conjunto com o Inovacred. O MPMe Inovadora (BNDES) lançado no mesmo ano pelo BDMG, apresentou desembolso superior a todos os outros produtos em 2014 (R $\$ 14$ milhões) e foi direcionado a uma única empresa. No ano seguinte, 5 projetos foram apoiados com desembolso total de $\mathrm{R} \$ 4,6$ milhões e ticket médio de $\mathrm{R} \$ 911$ mil. Em 2016, a linha de crédito permaneceu com nível de desembolso anual abaixo do Inovacred, porém acima do Pró-Inovação apoiou-se 16 projetos e o desembolso no ano foi igual a $\mathrm{R} \$ 7,8$ milhões. $\mathrm{O}$ crescimento do número de projetos, de 2015 para 2016, também é percebido e associado a mudança de estratégia da instituição. Vale destacar, que em 2014 o limite máximo aprovado foi superior ao pré-determinado pela descrição atual do produto ( $\mathrm{R} \$ 10$ milhões por beneficiário).

O Pró-Inovação teve a sua primeira liberação em setembro de 2011, após um período de crédito suprido para inovação. Nesse momento, os juros pré-fixados a $8 \%$ a.a. estavam acima da Selic anualizada igual 7,14\% a.a. ${ }^{7}$ Em 2012, as liberações são consideradas atípicas e justificadas por uma demanda extraordinária - 49 projetos com ticket médio igual a $\mathrm{R} \$ 584$ mil. Todavia, nota-se que a maior parte dos projetos ( 30 projetos de 49 apoiados nesse ano) foram apoiados no segundo semestre de 2012, quando a Selic anualizada estava a 8,4\% a.a, superior à taxa pré-fixada. Assim, o financiamento nesse ano pode estar associado, pelo menos em parte, a uma demand-push e a mudanças na taxa de juros básica da economia.

Em 2013, 12 projetos foram apoiados com ticket médio desembolsado superior ao ano anterior e igual a $\mathrm{R} \$ 837$ mil. Nesse sentido, o aumento da Selic não foi acompanhado por um crescimento da demanda, tudo mais constante. Com a introdução de novas linhas para inovação em 2014, o PróInovação mantém o desembolso e o número de projetos, praticamente, constante em relação ao ano de 2013. Em 2015, o desembolso descresse novamente - mais que 50\% - e o número de projetos aumenta de 10 para 12. No último ano analisado, apesar da mudança na meta comercial, o número de projetos financiados cai para 7 projetos de inovação com ticket médio igual a $\mathrm{R} \$ 782 \mathrm{mil}$.

\footnotetext{
${ }^{6}$ O BDMG trabalha com metas comerciais para direcionar o processo de busca por clientes. Nos anos anteriores a 2016 , o critério adotado como meta era valor total desembolsado pelas linhas de inovação no ano. Percebendo que essa realidade causaria concentração em determinados tipos de projeto, adicionou-se ao indicador de valor desembolsado, o número de projetos apoiados no ano.

7 Disponível em: <<https://www.bcb.gov.br/Pec/Copom/Port/taxaSelic.asp>> acesso dia 10/06/2017
} 
O produto exclusivo para empresas localizadas em parques tecnológicos, o Proptec, inaugurado junto com o Pró-Inovação é a única linha que possui trajetória de desembolso praticamente constante. Em relação, ao número de projetos, o ano de 2012, teve o maior resultado do período analisado - 7 projetos, desembolso anual de $\mathrm{R} \$ 2,97$ milhões e ticket médio de $\mathrm{R} \$ 424$ mil. Porém, o folego do produto financeiro não ultrapassou a quantidade de 3 projetos de inovação/ano com ticket médio de, aproximadamente, R\$508 mil. Dessa forma, é a linha de financiamento com menor desembolso e número de projetos financiados.

Gráfico 1: Evolução dos desembolsos para inovação por produto financeiro do BDMG, em valores de abril/2017

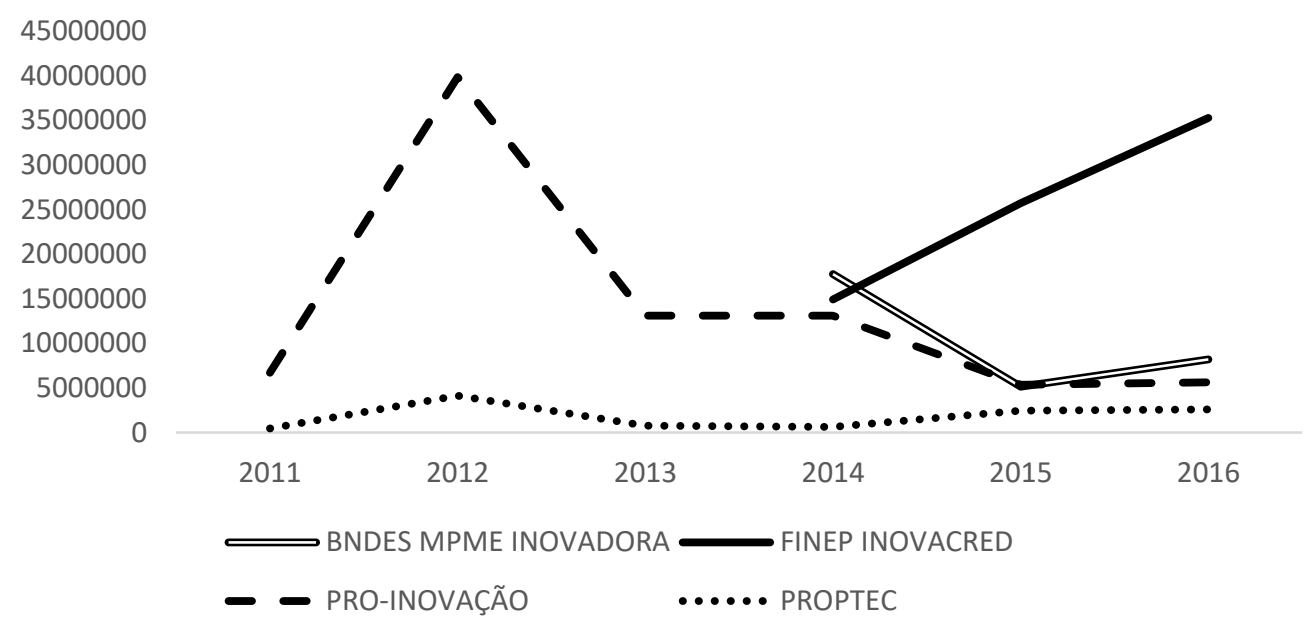

Fonte: Elaboração própria a partir de dados disponibilizados pelo BDMG.

\subsection{1 - Análise Setorial}

No período de 2011 até 2016, 48\% dos recursos das linhas de crédito do BDMG para inovação foram destinados para o setor de Comércio e Serviços - segundo a classificação de Setor Agregado do IBGE. O segundo setor com maior estoque de recursos acumulados é o de Máquinas e Equipamentos com 18\%, seguido pelo setor de Saneamento de Desenvolvimento Urbano responsável por $11 \%$ dos desembolsos. Vale destacar, que a análise setorial só é possível para o principal setor econômico de cada empresa, por causa de disponibilidade de dados - não sendo, necessariamente, a atividade de atuação do projeto de inovação.

Esse é o caso do principal setor, por valor desembolsado, do produto MPMe Inovadora (BNDES). Tem-se que a principal atividade da empresa que captou 57\% dos recursos acumulados, segundo o GRAF. 2, é o de Saneamento e desenvolvimento urbano. Todavia, o projeto de inovação se dá no processo de Fabricação de fertilizantes, subsetor da Fabricação de produtos químicos de uma única firma. Em relação ao Comércio e serviços, os Serviços de tecnologia da informação foram responsáveis por $15 \%$ do desembolso acumulado e por 8 das 22 empresas apoiadas pela linha do BNDES. Por fim, o setor de Máquinas de equipamentos engloba, exclusivamente, a Fabricação de equipamentos de informática, produtos eletrônicos e ópticos que foi responsável por financiar 3 projetos de inovação. 
Gráfico 2: Distribuição percentual dos desembolsos acumulados por setor agregado do MPMe Inovadora (2014-2016)

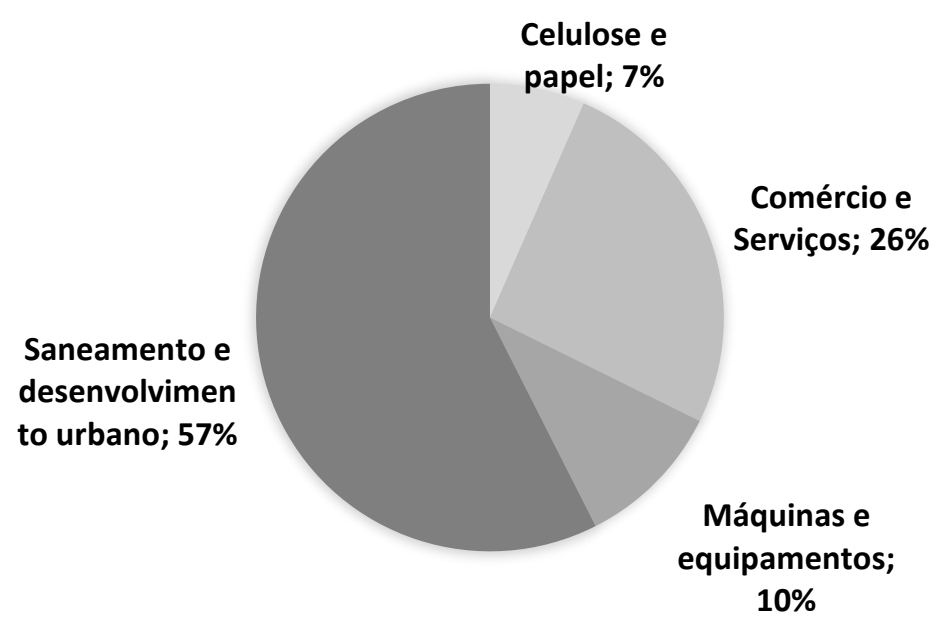

Fonte: Elaboração própria a partir de dados disponibilizados pelo BDMG

O desembolso acumulado do Inovacred, segundo o Gráfico 3, se concentra no setor de Comércio e serviços (59\%), principalmente no Serviços de tecnologia da informação e Serviços de arquitetura e engenharia, cada um responsável por $16 \%$ do desembolso total. Todavia, os recursos do primeiro se distribuem de forma menos concentrada, pois são apenas 6 projetos apoiados de TI contra 2 de Arquitetura e Engenharia. Já, para Máquinas e equipamentos divide-se em duas atividades: Fabricação de equipamento de informática, produtos eletrônicos e ópticos $(13,68 \%)$ e Fabricação de máquinas de equipamentos $(1,98 \%)$, financiando 2 projetos cada uma. O setor químico (14\%) é desagregado em Fabricação de produtos farmoquímicos e farmacêuticos $(13,45 \%)$ com 4 projetos de inovação aprovados e em Fabricação de produtos químicos (0,59\%) com 1 projeto.

Gráfico 3: Distribuição percentual dos desembolsos acumulados por setor agregado do Inovacred (2014-2016)

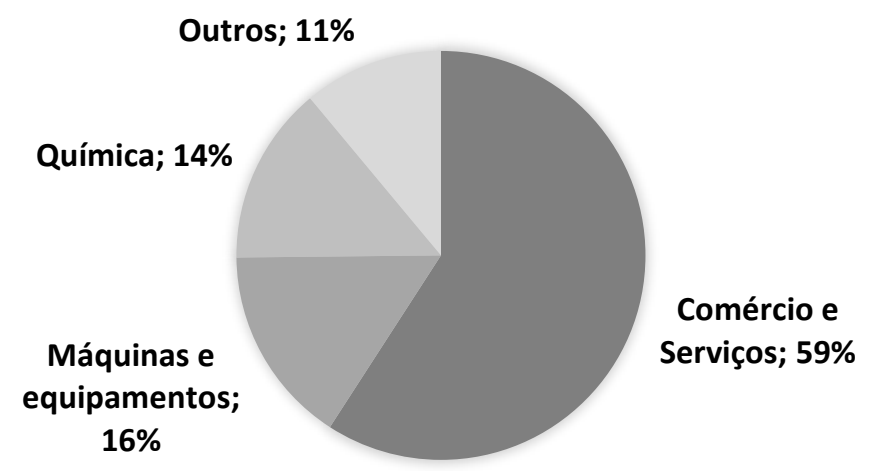

Fonte: Elaboração própria a partir de dados disponibilizados pelo BDMG

A distribuição setorial do recurso do Pró-Inovação (FAPEMIG) se mostra mais pulverizado segundo o GRÁFICO 4. As principais atividades, que compõem o setor de Comércio e serviços (39\% do desembolso acumulado) são os Serviços de tecnologia da informação (19,13\% do desembolso) com 24 projetos e Serviços de arquitetura e engenharia com 6 projetos financiados $(3,42 \%$ do desembolso). A atividade de Serviços de apoio administrativo prestados às empresas apesar de 
possuir participação percentual maior $(4,55 \%)$ no desembolso total do produto financeiro, apoiou apenas 3 projetos. Já, no setor de Máquinas e equipamentos apenas a atividade de Fabricação de equipamentos de informática, com 11 projetos, é responsável por 15,7\% do desembolso acumulado que equivale a aproximadamente $\mathrm{R} \$ 10$ milhões de reais correntes. $\mathrm{O}$ setor químico se subdivide em Fabricação de produtos farmoquímicos/farmacêuticos -4 projetos, $6,61 \%$ do desembolso acumulado - e Fabricação de produtos químicos -5 projetos e 7,15\% do desembolso acumulado. Em relação aos Produtos alimentícios e bebidas, o único subsetor é o de Fabricação de produtos alimentícios, que teve 5 projetos financiados no período acumulado. Os setores que compõem os "Outros" são Saneamento e desenvolvimento urbano; Eletricidade, gás e água; Editorial e gráfica; Borracha e plástico e Agricultura/pecuária.

Gráfico 4: Distribuição percentual dos desembolsos acumulados por setor agregado do PróInovação (2011-2016)

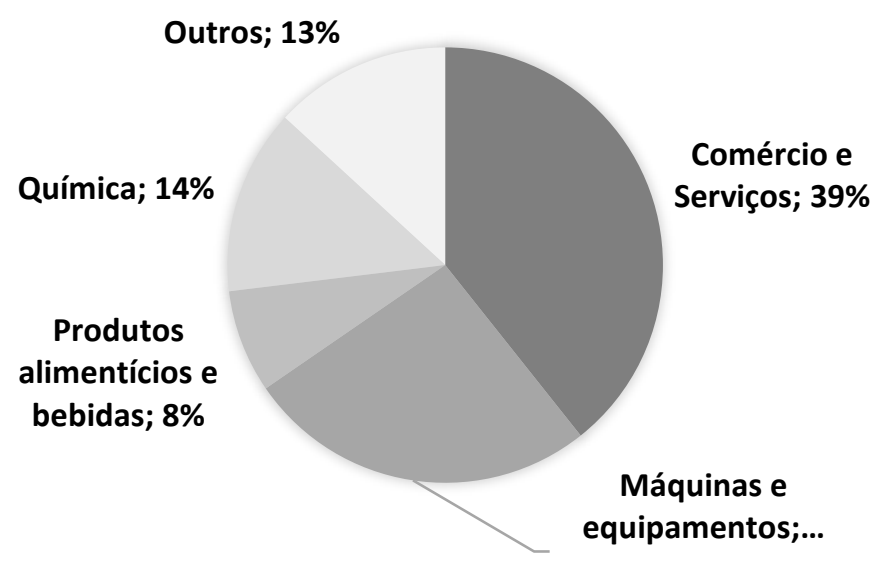

Fonte: Elaboração própria a partir de dados disponibilizados pelo BDMG

\section{2 - FIPS e Participação Direta}

A participação indireta do BDMG ocorre por meio de Fundos de Investimento em Participação (FIPs), enquanto a participação direta é dada pela posse de ações de duas empresas de tecnologia.

Segundo o Relatório de Gestão divulgado pelo BDMG em 2016, o Banco tornou-se cotista do fundo Criatec 3, lançado pelo BNDES em fevereiro - sexto fundo do qual o BDMG tornou-se cotista. A participação em FIPs objetiva assegurar investimentos de venture capital, principalmente para empresas de base tecnológica e de pequeno porte, com atuação prioritária nos setores de nanotecnologia, tecnologia da informação, biotecnologia, agronegócios e novos materiais. Em outubro de 2016, o Banco também se tornou cotista do novo Fundo de Investimentos Venture Brasil Central, que visa investir em empresas brasileiras inovadoras na região central do Brasil, nas áreas de Tecnologia da Informação e Comunicação (TIC), Tecnologias Agropecuárias ou Tecnologias em Saúde. Em 2016, o capital comprometido com sete fundos atingiu R \$ 48,2 milhões e até o momento, onze empresas mineiras foram apoiadas pelos fundos.

No que se refere à participação direta, o BDMG atua por intermédio da sua subsidiária BDMGTEC, através de participação no capital social de duas empresas localizadas em Minas Gerais do setor de semicondutores e biofármacos, ambos setores intensivos em conhecimento. Ao final de 2016, os valores integralizados chegaram a respectivamente, $\mathrm{R} \$ 28$ milhões na Biomm, fabricante de insulina, e R \$ 55 milhões na Unitec Semicondutores. 


\section{4 - Análise qualitativa das linhas de crédito do BDMG}

Essa seção apresenta uma análise qualitativa dos financiamentos do BDMG no período de 2011 até 2016, tendo como objeto de estudo as empresas financiadas para desenvolverem projetos de inovação - Inovacred (FINEP) e Pró-Inovação (FAPEMIG) - ou consideradas empresas inovadoras - MPMe Inovadora (BNDES) e Proptec (FAPEMIG). ${ }^{8}$ Atualmente, esse acompanhamento não é realizado pelo BDMG, pois os esforços internos se concentram na análise financeira da empresa.

A pesquisa foi feita a partir da aplicação de um questionário elaborado especificamente para esse fim. O público-alvo do estudo é composto por empresas do estado de Minas Gerais ${ }^{9}$, que obtiveram algum financiamento junto ao BDMG em alguma das modalidades e linhas mencionadas nas seções anteriores. Não foi preciso utilizar cálculo amostral, já que a pesquisa foi aplicada para a totalidade da população de interesse. Todavia, como algumas empresas obtiveram mais de um tipo de financiamento junto ao BDMG, optou-se por enviar a pesquisa referente ao produto financeiro mais recente. Os questionários foram eletronicamente enviados pela Gerência de Análises e Estudos do BDMG.

O questionário foi estruturado em quatro blocos de perguntas, conforme Quadro 2. O primeiro bloco se propôs a analisar o perfil das empresas que o BDMG apoia - como experiência em captar recursos do banco, know-how com inovação, outros financiamentos para inovação e motivação para inovar. O segundo bloco de perguntas corresponde ao projeto de inovação em si - status do projeto, tipo de inovação, fases do processo de inovação financiadas e dispêndios por atividades. A terceira parte tenta mensurar as externalidades dos projetos de inovação financiados - resultados, impacto na estratégia da empresa e obstáculos. Por último, perguntou-se sobre a linha de crédito, buscando entender pontos de melhoria - como prazo de carência, garantia e tempo de liberação.

Quadro 2: Descrição das variáveis do questionário

\begin{tabular}{lll}
\hline \multicolumn{1}{c}{ Variáveis } & \multicolumn{1}{c}{ Descrição } & Escala de medida \\
\hline Perfil da empresa & Posição dentro da empresa & Aberta \\
\hline Função & Nível de escolaridade & Aberta \\
Escolaridade & Captação de outras linhas do BDMG & Binária (sim, não) \\
Know-how BDMG & Experiência com projetos de inovação & Binária (sim, não) \\
Know-how Inovação & Recursos de terceiros para inovação & Binária (sim, não) / Aberta \\
Financiamento externo & Players que fomentaram a busca pela inovação da empresa & Ordinal, 0-5 \\
Motivações & & \\
\hline Projeto de inovação & Produto, processo, organizacional ou marketing & Múltipla escolha \\
\hline Tipo de inovação & Utilização dos recursos por fases da inovação & Ordinal, 0-5 \\
Etapas da inovação & Distribuição dos dispêndios por atividade & Numérico \\
Gastos dos recursos totais & Dispêndios da linha do BDMG por atividade & Numérico \\
Gastos com o recurso BDMG & Concluído, em andamento e abandonado & Múltipla escolha \\
Status do projeto & & Aberta \\
\hline Resultados & Razão para descontinuação do projeto de inovação & Múltipla escolha / Ordinal, 0-5* \\
\hline Motivo do abandono & Grau de novidade do produto/serviço ou processo & Múltipla escolha/ Ordinal, 0-5 \\
Resultados do projeto & Resultado para estratégia da empresa & Ordinal, 0-5 \\
Impacto para a empresa & Dificuldades para desenvolver o projeto de inovação & \\
Desafios & & Múltipla escolha \\
\hline Linha de crédito & Itens de dificuldade na obtenção de crédito do BDMG & \\
\hline Obstáculos & & \\
\hline Fonte: Elaboração própria & A opção de múltipla-escolha foi a escala de medida para os projetos de inovação concluídos e os projetos em andamento, em função dos resultados \\
parciais, tiveram mensuração em escala ordinal de expectativa, tanto para a variável de resultado do projeto de inovaça, quanto para o impacto na \\
estratégia da empresa.
\end{tabular}

\footnotetext{
${ }^{8}$ Como só houve dois financiamentos do Inovacred Expresso (FINEP) para empresas inovadoras até o final de 2016, excluiu-se a linha de crédito da análise.

${ }^{9}$ Segundo a PINTEC (2014), Minas Gerais representa 11,8\% das empresas brasileiras que implementaram inovação.
} 
Pelo fato das empresas classificadas como inovadoras não precisarem apresentar projeto para obtenção do crédito, o questionário teve que ser adaptado. Apesar disso, como veremos a seguir, a totalidade das empresas inovadoras que responderam possuíam um projeto de inovação em andamento. Foram solicitados detalhes apenas do projeto de inovação anterior ou simultâneo ao financiamento da empresa inovadora, para aquelas cujo projeto obteve financiamento do BDMG. Nesse caso, a empresa teria que ter captado recursos para inovação, pelo menos, duas vezes.

\section{1 - Resultados}

E possível observar que as linhas de crédito mais relevantes, tanto em número de projetos quanto em valor desembolsado, são o Pró-Inovação (FAPEMIG) e o Inovacred (FINEP). Por isso, ambos os produtos financeiros serão analisados de maneira mais detalhada e comparativamente. A taxa de resposta dos questionários foi acima do esperado: MPMe Inovadora (74\% - 17/23 empresas); Inovacred (50\% - 16/32); Pró Inovação (38\% - 34/89 empresas) e o Proptec não obteve nenhum questionário respondido completamente (0/8 empresas).

Já foi apresentado, anteriormente, que o valor máximo liberado pelo Inovacred é superior ao PróInovação e, por isso, o ticket-médio e o porte das empresas financiados são maiores. Os resultados, apresentados na TAB. 5, sugerem que as empresas que captaram o Inovacred possuem maior knowhow em obter recursos com o BDMG, do que as empresas do Pró-Inovação, pois 56\% dos respondentes do Inovacred haviam contratado outros financiamentos com o banco exceto, para inovação. As empresas financiadas pelo Pró-Inovação, todavia, possuem maior experiência em desenvolver projetos de inovação, visto que $74 \%$ das empresas já haviam desenvolvido, pelo menos, um projeto inovador anterior a aquele financiado pelo BDMG. As motivações para inovar foram as mesmas: mercado em expansão, clientes e surgimento de recursos para inovação. O resultado clientes reafirma o indício da análise setorial, de que a maioria das empresas são prestadoras de serviço e não desenvolvem a atividade fim. A opção surgimento de recursos para inovação, apesar da possibilidade de viés, é relevante na medida em que a existência da linha de crédito pode, por si só, incentivar as firmas a pensar no processo de inovar.

Em relação ao projeto de inovação, pode-se inferir que a maioria das empresas inovaram em produto: $100 \%$ dos respondentes do Inovacred contra $83 \%$ do Pró-Inovação, apesar do primeiro ter o conceito de inovação mais flexível, que inclui inovação organizacional e de marketing ${ }^{10}$. A PINTEC (2014) apresenta que 30\% das empresas mineiras inovam em produto. O percentual mais elevado para as empresas do BDMG, pode estar ligado a dificuldade de entendimento do que é inovação para os clientes do banco.

Dada a complexidade do processo de inovação, optou-se por avaliar somente o "caminho do processo da inovação", que engloba a ideação, o desenvolvimento e a comercialização da inovação (JONASH e SOMMERLATTE, 2001). Nesse sentido, observa-se que ambos os recursos reembolsáveis do BDMG na TAB. 5 atuam, principalmente, nas fases de desenvolvimento do produto, da tecnologia e na comercialização. É importante observar se essas fases estão se sobrepondo a outros agentes de fomento ou se o BDMG está atuando de maneira complementar a políticas estaduais e federais de fomento da inovação.

Mais projetos de inovação foram concluídos para a linha Pró-Inovação, em relação ao Inovacred, possivelmente por ser um produto mais antigo. A princípio eles, também, parecem ser mais disruptivos, pois apresentam projetos concluídos com um maior grau de novidade da inovação. Das cinco empresas que tiveram resultados inovadores para o mundo, apenas uma não tinha experiência com projetos de inovação anteriores a aquele financiado pelo BDMG. Além disso, quatro das cinco empresas com experiência tiveram financiamento de fontes externas. Todavia, apenas uma empresa obteve recursos não reembolsáveis do $\mathrm{CNPq}$, enquanto as outras contaram com crédito de bancos comerciais ou recursos próprios. A tendência se mostra a mesma para os projetos do Pró-Inovação em andamento. Das oito empresas que responderam estarem pelo menos confiantes que conseguirão ofertar uma novidade mundial, cinco já estiveram envolvidas em outros projetos e tiveram apoio ou

\footnotetext{
${ }^{10}$ Ver página 19 do subcapítulo Linhas de Crédito do BDMG.
} 
financiamento externo da FINEP, do CNPq, do Sebraetec e de linhas de crédito de bancos comerciais. Em outros termos, conclui-se para os projetos de inovação que, a exemplo de Dosi (1988), “(...) os processos de busca tecnológica em cada firma são também processos cumulativos. O que a firma pode esperar fazer tecnologicamente no futuro está estreitamente condicionado pelo que ela foi capaz de fazer no passado" (p.1130), e isso parece valer também para a capacidade de financiar o processo de inovação.

Diferentemente, as quatro empresas com maior grau de novidade do Inovacred (mercado nacional), tiveram um baixo percentual de envolvimento em projetos de inovação anteriores, sendo apenas uma empresa das quatro.

A falta de recursos próprios foi o principal obstáculo a se inovar, para $81 \%$ das empresas que tiveram financiamento do Inovacred. Essa variável é seguida pela dificuldade em encontrar pessoal qualificado (capital humano) e suporte técnico/científico e laboratorial (infraestrutura), com 63\% das respostas. O grau de concentração dos principais desafios para as empresas do Pró-Inovação é menor: $59 \%$ afirmaram sobre a falta de pessoal qualificado, seguido pela falta de financiamento externo com $56 \%$ e da falta de recursos próprios (53\%). A pergunta específica sobre os desafios que as linhas de crédito do BDMG oferecem as empresas, tiveram respostas quase unânimes em torno do Tempo de liberação e da Documentação exigida.

A taxa de resposta da linha MPMe Inovadora do BNDES, foi igual a 73,9\% (17/23), - a mais alta em comparação com as outras linhas de crédito para inovação. Dos respondentes, $30 \%$ já haviam solicitado crédito ao BDMG anteriormente para outros fins, sendo que apenas uma teve o pedido negado. Em sua totalidade, as empresas responderam que usaram os recursos da linha para alguma atividade inovativa, que não se destina, necessariamente, a um projeto de inovação específico. Todavia, apenas quatro empresas responderam que não tinham projeto específico em andamento quando demandaram o crédito ou após obter os recursos do MPMe. Porém, a descrição de como os recursos foram gastos, sugere que as respondentes estavam falando de atividades específicas e não genéricas, como a construção de infraestrutura laboratorial, por exemplo. Possivelmente, as empresas responderam que o projeto não era específico por não haver clientes aguardando a finalização do projeto. Assim, concluiu-se que a totalidade das empresas captaram recursos com projeto específico em andamento.

Em relação as fases do processo de inovação, $76 \%$ dos respondentes informaram que o recurso financeiro foi muito importante nas etapas de desenvolvimento tecnológico e de produto. Além disso, $50 \%$ das empresas que indicaram ter projeto específico em andamento, responderam que obtiveram financiamentos externos anteriores ou simultâneos ao MPMe. Das sete empresas respondentes, apenas uma captou junto ao BDMG o recurso Pró-Inovação. ${ }^{11}$ As outras obtiveram recursos na FAPEMIG (uma empresa) em edital com a CEMIG, na FINEP (uma empresa), Bancos Comerciais (três empresas) e outros (uma empresa). O principal motivo para captação em Banco Comerciais, alegados pelos respondentes, foi o tempo de liberação mais ágil ou por causa do desconhecimento do produto de inovação do BDMG.

Em relação ao Proptec (FAPEMIG), de oito empresas apenas duas responderam o questionário de maneira incompleta. Ambas as empresas, interromperam o preenchimento no momento antes de indicar o percentual de recursos totais disponíveis para o projeto, segundo as atividades listadas no campo de resposta. Destaca-se que as empresas respondentes já haviam desenvolvido outros projetos de inovação, anteriores ao crédito do Proptec, e tiveram financiamento externo/apoio de outras instituições como a FAPEMIG, o CNPq e o Sebraetec.

\footnotetext{
${ }^{11}$ Todavia, sabe-se que no total das 23 empresas financiadas pelo MPMe, 4 foram financiadas anteriormente pelas linhas Proptec ou Pró-Inovação.
} 
Tabela 5 - Qualificação da Carteira do BDMG - Resultados do Questionário de Inovação

\begin{tabular}{|c|c|c|c|c|}
\hline \multirow[b]{2}{*}{ Perfil da empresa } & \multicolumn{2}{|c|}{ INOVACRED } & \multicolumn{2}{|c|}{ PRO-INOVAÇAO } \\
\hline & $\%(100 \%)$ & $\begin{array}{c}\text { Número de respondentes } \\
(\mathrm{N}=16)\end{array}$ & $\%(100 \%)$ & Número de respondentes $(\mathrm{N}=34)$ \\
\hline Know-how BDMG & $56 \%$ & 9 & $18 \%$ & 6 \\
\hline Know-how Inovação & $44 \%$ & 7 & $74 \%$ & 25 \\
\hline Financiamento externo & $71 \%$ & 12 & $65 \%$ & 22 \\
\hline Motivações* & $\begin{array}{l}93 \% \text { Mercado em expansão, } 81 \% \\
\text { Clientes, } 75 \% \text { Surgimentos de recursos }\end{array}$ & 16 & $\begin{array}{l}90 \% \text { Mercado em expansão, } 86 \% \text { Clientes, } \\
41 \% \text { Surgimentos de recursos }\end{array}$ & 33 \\
\hline \multicolumn{5}{|l|}{ Projeto de inovação } \\
\hline Tipo de inovação & $\begin{array}{l}100 \% \text { produto, } 25 \% \text { processo, } 6 \% \\
\text { organizacional e marketing }\end{array}$ & $\begin{array}{l}16 \text { produtos, } 4 \text { processos, } 1 \\
\text { organizacional e } 1 \text { marketing }\end{array}$ & $\begin{array}{l}83 \% \text { produto, } 33 \% \text { processo, } 9 \% \\
\text { organizacional e } 3 \% \text { marketing }\end{array}$ & $\begin{array}{l}26 \text { produtos, } 11 \text { processos, } 3 \\
\text { organizacional e } 1 \text { marketing }\end{array}$ \\
\hline Etapas da inovação & $\begin{array}{l}\text { 93\% Desenvolvimento produto; } 75 \% \\
\text { tecnológico; } 43 \% \text { comercialização; } 37 \% \\
\text { pesquisa aplicada e produção }\end{array}$ & - & $\begin{array}{l}77 \% \text { Desenvolvimento produto; } 67 \% \\
\text { tecnológico; } 40 \% \text { comercialização; } 36 \% \\
\text { produção e } 31 \% \text { pesquisa aplicada }\end{array}$ & -5 \\
\hline Gastos dos recursos totais & $\begin{array}{l}\text { 41\% P\&D; 35\% Máq. Equip.; } 16 \% \\
\text { Padronização; } 15 \% \text { Outros }\end{array}$ & 16 & $\begin{array}{l}42 \% \text { P\&D; } 29 \% \text { Máq. Equip.; } 11 \% \\
\text { Comercialização; } 10 \% \text { Outros }\end{array}$ & 33 \\
\hline Gastos com o recurso BDMG & $\begin{array}{l}\text { 40\% Máq. Equip.; } 38 \% \text { P\&D; } 25 \% \\
\text { Outros; } 15 \% \text { Padronização }\end{array}$ & 16 & $\begin{array}{l}\text { 47\% P\&D; } 29 \% \text { Máq. Equip.; 15\% Outros; } \\
\text { 12\% Marketing; } 9 \text { Comercialização }\end{array}$ & \\
\hline Status do projeto & $37 \%$ concluídos e $63 \%$ em andamento & 6 concluídos e 10 em andamento & $\begin{array}{l}54 \% \text { concluídos, } 36 \% \text { em andamento e } 10 \% \\
\text { abandonado }\end{array}$ & $\begin{array}{l}16 \text { concluídos, } 15 \text { em andamento e } \\
3 \text { abandonados }\end{array}$ \\
\hline \multicolumn{5}{|l|}{ Resultados } \\
\hline Motivo do abandono** & \multicolumn{2}{|l|}{-} & \multicolumn{2}{|c|}{ Inovação não foi aceita pelo mercado; conflitos internos a firma } \\
\hline Resultados do projeto concluído & \multicolumn{2}{|c|}{$\begin{array}{l}4 \text { produtos novos ( } 4 \text { para o Brasil); } 3 \text { serviços novos (1 para o Brasil) e } 4 \\
\text { processos novos (1 para o Brasil) }\end{array}$} & \multicolumn{2}{|c|}{$\begin{array}{l}8 \text { produtos novos ( } 3 \text { para o Brasil e } 5 \text { para o mundo); } 3 \text { serviços novos ( } 1 \text { para o } \\
\text { Brasil) e } 6 \text { processos novos ( } 2 \text { para o Brasil e } 1 \text { para o mundo) }\end{array}$} \\
\hline Resultados do projeto em andamento & \multicolumn{2}{|c|}{$\begin{array}{l}9 \text { produtos novos ( } 6 \text { para o Brasil e } 3 \text { para o mundo); } 5 \text { serviços novos ( } 5 \text { para } \\
\text { o Brasil) e } 3 \text { processos novos ( } 3 \text { para o Brasil) }\end{array}$} & \multicolumn{2}{|c|}{$\begin{array}{l}8 \text { produtos novos ( } 8 \text { para o Brasil e } 4 \text { para o mundo); } 4 \text { serviços novos ( } 4 \text { para o Brasil } \\
\text { e } 2 \text { para o mundo) e } 8 \text { processos novos ( } 5 \text { para o Brasil e } 3 \text { para o mundo) }\end{array}$} \\
\hline Impacto para a empresa & \multicolumn{2}{|c|}{$\begin{array}{l}83 \% \text { ampliaram a gama de bens ofertados; } 66 \% \text { melhoraram a qualidade dos } \\
\text { bens ofertados; } 66 \% \text { abriram novos mercados no Brasil e } 50 \% \text { reduziram } \\
\text { custos de produção e perceberam de novas oportunidades tecnológicas }\end{array}$} & \multicolumn{2}{|c|}{$\begin{array}{l}73 \% \text { ampliaram a gama de bens ofertados; } 53 \% \text { abriram de novos mercados no } \\
\text { Brasil; } 40 \% \text { reduziram custos; } 33 \% \text { abriram de novos mercados no exterior e } \\
\text { perceberam de novas oportunidades tecnológicas }\end{array}$} \\
\hline Impacto esperada para a empresa & \multicolumn{2}{|c|}{$\begin{array}{l}100 \% \text { esperam manter a participação no mercado; } 80 \% \text { melhorar a qualidade } \\
\text { dos bens e } 70 \% \text { ampliar a participacão no mercado }\end{array}$} & \multicolumn{2}{|c|}{$\begin{array}{l}90 \% \text { esperam abrir novos mercados; } 80 \% \text { ampliar a gama de bens ofertados e } \\
\text { melhorar a qualidade; } 60 \% \text { perceber novas oportunidades tecnológicas }\end{array}$} \\
\hline Desafios & \multicolumn{2}{|c|}{$\begin{array}{l}81 \% \text { falta de recursos próprios; } 63 \% \text { falta de pessoal qualificado e suporte } \\
\text { tecno/cient. Laboratorial; } 56 \% \text { pressão da concorrência }\end{array}$} & \multicolumn{2}{|c|}{$\begin{array}{l}59 \% \text { falta de pessoal qualificado; } 56 \% \text { falta de financiamento externo; } 53 \% \text { falta de } \\
\text { cursos próprios; } 35 \% \text { falta de fornecedores especializados e problemas com regulação }\end{array}$} \\
\hline
\end{tabular}

Fonte: Elaboração própria

Notas: $(*)$ Motivações fortes ou muito fortes; $(* *)$ Um dos respondentes ignorou a pergunta aberta. 


\section{5 - Considerações Finais}

Esse artigo possui um caráter essencialmente descritivo, tendo resultado mais de uma necessidade interna do BDMG em avaliar suas iniciativas para inovação, combinado à oportunidade de obter informações sobre as empresas que buscam por financiamento para o processo de inovação em Minas Gerais. Desse ponto de vista, dentro dos limites possíveis para o uso de informações sobre clientes do banco, esse trabalho se insere no rol das contribuições preliminares.

A atuação do BDMG em inovação é bastante recente, assim como os incentivos Federais. A lei $\mathrm{n}^{0} 10.973$ da inovação é de dezembro de 2004, enquanto o primeiro produto financeiro do banco é de setembro de 2011. Isso significa, que há ainda muito espaço para o aprendizado, principalmente, internamente ao Banco.

O BDMG tem expertise em tratar das especificidades de Minas Gerais, mas a concentração setorial dos recursos para inovação sugere a necessidade de maiores esforços para levar esses recursos a atividades mais diversificadas. Para tanto, é necessário ter um conhecimento mais robusto sobre o sistema de inovação no estado, do ponto de vista geral e das competências necessárias ao próprio banco para internalizar a dimensão da inovação em suas rotinas, processo e produtos.

Há espaço para o aperfeiçoamento dos produtos financeiros existentes, na medida em que se verifica que outras agencias e estados oferecem opões melhores em termos do custo do financiamento. Sugere-se, nesse sentido, que o Proptec seja repensado para poder englobar um número maior de empresas, por exemplo, instaladas em incubadoras ou que foram aceleradas pelo SEED - única aceleradora com recursos públicos do país.

O Banco tem a possibilidade de construir diferenciais a partir da diversificação das fontes de capitação. Enquanto agente de repasse de recursos das agências federais BNDES e FINEP o banco pode melhorar a sua eficiência ao ajustar subsídios às taxas de juros ou flexibilizar garantias e tempo de carência, por exemplo. Mas, ao adquirir capacidade própria de capitação, diretamente de agentes ou do governo estadual, via fundo específico de inovação, o banco pode atuar de forma complementar aos recursos provenientes das outras fontes e, assim, estabelecer trajetórias de desenvolvimento mais independentes.

É possível evoluir também em relação às formas de financiamento. Enquanto os empréstimos cumprem papel significativo no financiamento do sistema de inovação, a participação direta em empresas, em associação com uma postura mais ativa, permitiria ao banco ser um agente extremamente relevante na estratégia de desenvolvimento do estado, ao fomentar setores com grande potencial de inovação, que por outras vias seriam negligenciados. A participação nas decisões dessas organizações conferiria ao BDMG condições de prevenir ou dificultar desvios e corrigir a estratégia de inovação, garantindo, em alguma medida, o retorno social esperado.

Como os resultados do processo de inovação sobre o desenvolvimento econômico são de longo prazo, é necessário institucionalizar os mecanismos de apoio ao mesmo tempo em que se garante flexibilidade para que esses mecanismos evoluam. Nesse sentido, o banco pode assumir um papel importante nessa institucionalização. Por exemplo, ao capitar recursos diretamente com metas claras de fomento à inovação e ao assumir compromissos vinculados a resultados de longo prazo, que não sejam puramente pecuniários, mas atrelados a um desenvolvimento sustentável.

Há necessidade de que o banco se posicione de forma mais proativa, no sentido de melhorar os canais de informação sobre seus produtos para inovação e outros produtos complementares. Atualmente, o canal de acesso virtual não informa de maneira fácil e clara dados básicos, como a taxa de juros e garantias, dos produtos de inovação, não divulga o nome das linhas de crédito e não apresenta uma definição do que o banco entende como inovação. 
Também é possível melhorar o monitoramento das empresas clientes para gerar informações mais consistentes sobre o contexto da inovação dentro da empresa, no setor e no estado e, assim, aperfeiçoar continuamente seus produtos e serviços, além da sua atuação. Para isso, torna-se necessário ainda o esforço de padronizar e agrupar as informações já existentes sobre os projetos e empresas apoiados.

\section{REFERÊNCIAS}

CAMPOLINA, Clélio D. Economia da Ciência, Tecnologia e Inovação: Fundamento Teóricos e a Economia Global. $1^{\text {a }}$ ed. Curitiba: Prisma, 2017. [Introdução]

CAMPOLINA, Clélio D. O Papel das Inovações e das Instituições no Desenvolvimento Local. Anais do XXIX Encontro Nacional de Economia. 2001

CAMPOS, Bruno C. e RUIZ, Ana U. Padrões Setoriais de Inovação na Indústria Brasileira. Revista Brasileira de Inovação. Revista Brasileira de Inovação. Rio de Janeiro, 2009.

CAVALCANTE, Anderson. RAPINI, M.S.; LEONEL. S.G. O financiamento da inovação. Em: RAPINI, M.S; SILVA, L.A.; ALBUQUERQUE, E. M. Economia da Ciência, Tecnologia e Inovação: Fundamento Teóricos e a Economia Global. $1^{\text {a }}$ ed. Curitiba: Prisma, 2017. p. 199237.

CHESNAIS, F.; SAUVIAT, C. O financiamento da inovação no regime global de cumulação dominado pelo capital financeiro. Em: LASTRES, H. M. M.; CASSIOLATO, J. E; ARROIO, A. (eds.) Conhecimento, Sistemas de Inovação e de Desenvolvimento. Rio de Janeiro: Editora UFRJ e Contraponto, 2005.

CHIARINI, Túlio. Economia da Ciência, Tecnologia e Inovação: Fundamento Teóricos e a Economia Global. $1^{\text {a }}$ ed. Curitiba: Prisma, 2017, p. 131-162.

CHRISTENSEN, J. L. The role of Finance in National System of Innovation. EM: LUNDVALL, B. National Systems of Innovation. London: Pinter Publishers, 1992.

COSTA, Achyles B. A Teoria da Firma: crítica à visão neoclássica e enfoque heterodoxo. Texto para discussão do Programa de Pós-Graduacão em Economia. Porto Alegre, 2016, p. 43.

DOSI, Giovanni. Sources, procedures, and microeconomic effects of innovation. Journal of Economic Literature, vol. 26, p. 1120-1171. 1988

DOSI, Giovanni. Finance, innovation and industrial chance. Journal of Economic Behavior \& Organization. Elsevier. 1990.

FREEMAN, Chris. The "National System" of Innovation in historical perspective. Cambridge Journal of economics. 1995

EDUCATIONAL FOUNDATION OF NUCLEAR SCIENCE. The Physical Problem of Big Science. Inc. Bulletin of the Atomic Scientists, vol. 22 (2), 1966.

HIMMELBERG, C. P.; PETERSON, B. C.R\&D and Internal Finance: A Panel Study of Small Firms in High-Tech Industries, Review of Economics and Statistics 76: 38-51, 1994.

JONASH, R. S.; SOMMERLATTE, T. O valor da inovação: como as empresas mais avançadas atingem alto desempenho e lucratividade. Rio de Janeiro: Campus, 2001.

KUZNETS, S. Economic Growth and Structure: selected essays. Heinemann Educational. 1966 
LEIPONEN, Aija; DREJER, Ina. What exactly are technological regimes? Intra-industry heterogeneity in the organization of innovation activities. Science Direct: Elsevier. 2007

LEONEL, S. Mitos e verdades da indústria de venture capital. Tese de doutorado. Universidade Federal de Minas Gerais. Belo Horizonte, 2014.

LOPES, Herton C. O desenvolvimento econômico: uma proposta de abordagem teórica evolucionária e institucionalista. Estud. Econ., vol.45 (02). São Paulo: Scielo. 2015

MAZZUCATO, Mariana. The Entrepreneurial State. London: Demos, 2014.

MAZZUCATO, Mariana; SEMIENIUK, Gregor. Public financing of innovation: new questions. Oxford Review of Economic Policy, vol. 33, nº 01, 2017. p. 24-48. 2017

MARX, Karl; ENGELS, Friedrich ([1848]2010). Manifesto Comunista. São Paulo: Boitempo. MYERS, Stewart C.; MAIJUF, Nicholas S. (1984). Corporate financing and investment decisions when firms have information that investors do not have. Journal of Financial Economics. 13 (2): 187-221.

RAPINI, Márcia S. O Financiamento aos Investimentos em Inovação no Brasil. Tese de Doutorado pela Universidade Federal do Rio de Janeiro (UFRJ). Rio de Janeiro, 2010.

RELATORIO DE GESTAO 2016. Bando de Desenvolvimento de Minas Gerais. Belo Horizonte. 2016

RESENDE, Marco Flávio. O circuito finance-investimento-poupança-funding em economias abertas. Revista de Economia Política, Vol. 28 (109), Belo Horizonte, 2008.

RETORNOS DOS DESEMBOLSOS DO BDMG PARA ECONOMIA DE MINAS GERAIS: 2007-2016. Banco de Desenvolvimento de Minas Gerais. Belo Horizonte. 2016

ROSENBERG, Nathan [1986]. Quão exógena é a Ciência? Revista Brasileira de Inovação, Volume 5, Número 2, Campinas, 2006.

PAVITT, Keith. Sectorial Patterns of Technical Change: Towards a Taxonomy and Theory. Research Policy, Amsterdã, Vol.13, no. 6. University of Sussex, Brigton, Reino Unido. 1984. pp. 343-373

SILVA, Débora O. et al. Modelos para gestão da inovação: revisão e análise da literatura. Production, vol. 24., n. 2, 2014. p. 477-490

SCHUMPETER, Joseph. [1911] Teoria do Desenvolvimento Econômico: Uma investigação sobre lucros, capital, crédito, juro e o ciclo econômico. São Paulo, Nova Cultural (Os Economistas), 1998.

SCHUMPETER, Joseph. The Instability of Capitalism. The Economic Journal, Vol. 38 (151), Setembro, 1928. 